\title{
Diagnóstico laboratorial da raiva na região oeste do Estado de São Paulo
}

\author{
Laboratory diagnosis of rabies in the west \\ region of São Paulo State
}

\author{
Avelino Albas', Paulo Tadeu Zoccolaro', \\ Talita Zacarias Rosa ${ }^{1}$ e Elenice Maria Sequetin Cunha ${ }^{2}$
}

\begin{abstract}
RESUMO
O laboratório do Pólo da Alta Sorocabana, Presidente Prudente, SP e Instituto Biológico de São Paulo, SP, realizaram avaliação do diagnóstico laboratorial da raiva no período de 1996 a 2003 na região oeste do Estado de São Paulo. Para tal, se fez uso dos testes de imunofluorescência direta e prova biológica (inoculação em camundongos) em 4.950 amostras encaminhadas para análise envolvendo as espécies canina, felina, bovina, quiróptera (morcego) e outras (eqüina, caprina, suína e roedores). Detectou-se a presença de 74 amostras positivas, sendo que destas, 58 (78,4\%) foram referentes a quirópteros não hematófagos e $16(21,6 \%)$ para bovinos. O presente estudo epidemiológico constatou que, apesar do alto índice de positividade nos quirópteros, não houve um surto de raiva nestas espécies na região de Presidente Prudente no período estudado, porque o aumento no índice de positividade foi decorrente do significativo aumento de amostras de quirópteros encaminhadas ao laboratório para pesquisa do vírus rábico.
\end{abstract}

Palavras-chaves: Raiva. Diagnóstico laboratorial. Vigilância epidemiológica.

\begin{abstract}
The Pólo da Alta Sorocabana laboratory, Presidente Prudente, SP, Brazil, and the Biological Institute in São Paulo State, performed an evaluation of rabies diagnosis from 1996 to 2003 in the west region of São Paulo State. For the tests, the laboratories used direct immunofluorescence and mice inoculation in 4,950 samples, that were sent for analysis involving dogs, cats, cattle, chiroptera (bats) and other animals. According to the results, the laboratories found 74 positive samples; of which 58 (78.4\%)were non-hematophagous bats and $16(21.6 \%)$ related to cattle. The present epidemiological study verified that in spite of the high positive index in chiroptera compared to the other species, there was not an outbreak of rabies in the species in the region of Presidente Prudente, from 1996 to 2003 but a rise in the positive index due to a marked increase in the number of chiroptera samples sent to the laboratories for virus rabies research.
\end{abstract}

Key-words: Rabies. Laboratorial diagnosis. Epidemiologic surveillance.

Segundo informe da Organização Panamericana de Saúde $(\mathrm{OPAS})^{7}$, em 2001 nos países das Américas foram notificados 60 casos de raiva humana, sendo que o principal transmissor foi o cão e em segundo lugar os morcegos (hematófagos e não hematófagos). Em relação à raiva animal, os países notificaram um total de 12.540 casos, sendo que 7.779 (62\%) ocorreram na América do Norte, 4.715 (37,6\%) na América Latina e 46 $(0,4 \%)$ no Caribe.

A raiva dos herbívoros é responsável por enormes prejuízos econômicos na América Latina, em torno de 30 milhões de dólares/ano e no Brasil este valor se aproxima de 15 milhões de dólares/ano, com a morte aproximada de 40.000 bovinos $/ \mathrm{ano}^{3}$.

0 laboratório de diagnóstico da raiva é essencial para orientação do programa de controle, bem como, para orientar a vigilância epidemiológica visando a profilaxia nas áreas geográficas onde os casos positivos forem notificados. Desde 1995, o laboratório do Pólo da Alta Sorocabana vem realizando este tipo de diagnóstico para aproximadamente 53 municípios que compõem a $10^{\mathrm{a}}$ Região Administrativa do Estado de São Paulo. Presidente Prudente é a sede desta Região Administrativa e

1. Agência Paulista de Tecnologia dos Agronegócios (APTA), Pólo da Alta Sorocabana, Presidente Prudente, SP. 2. Seção de Raiva do Instituto Biológico, São Paulo, SP. Endereço para correspondência: Dr. Avelino Albas. Rua Fernão Sales 555, 19570-000 Regente Feijó, SP.

Telefax: 5518 222-8688

e-mail: nrpp@ig.com.br

Recebido para publicação em 28/9/2004

Aceito em 10/8/2005 
geograficamente localiza-se no Sudoeste do Estado de São Paulo, latitude $22^{\circ} 07^{\prime} 04^{\prime \prime}$ e longitude $51^{\circ} 22$ '57'.

Em 22/07/2001 veio a óbito, por raiva, uma mulher de 53 anos de idade no município de Dracena, que pertence à região de Presidente Prudente, com uma história epidemiológica de agressão por gato que havia tido contato com morcego 5 . Este fato mudou o perfil epidemiológico da região com relação a esta zoonose.

Neste trabalho, os autores tiveram por objetivo avaliar o diagnóstico laboratorial da raiva na região de Presidente Prudente (Oeste do Estado de São Paulo) no período compreendido entre os anos 1996 a 2003.

\section{MATERIAL E MÉTODOS}

Amostras para exame e testes para o diagnóstico da raiva. As amostras para exame foram provenientes de diferentes espécies animais, sendo que os quirópteros constituíram maior número, seguido de caninos, felinos, bovinos e com menor frequiência, classificadas como outras espécies: eqüinos, suínos, caprinos, símios e roedores. Foram utilizados fragmentos do sistema nervoso central (hipocampo, cerebelo e córtex) para o preparo de lâminas e inóculos. 0 diagnóstico laboratorial da raiva foi realizado empregando-se o teste de imunofluorescência direta, conforme descrito por Dean e Abelseth ${ }^{2}$ e a prova biológica (inoculação em camundongos) de acordo com 0 método preconizado por Koprowsky ${ }^{4}$.

\section{RESULTADOS}

No período de 1996 a 2003, foram encaminhadas 4.950 amostras para diagnóstico laboratorial da raiva referentes às espécies canina, felina, bovina, quiróptera e outras, sendo que destas, 74 foram positivas envolvendo apenas os bovinos e quirópteros. Quanto aos bovinos, de 205 amostras analisadas, $16(7,8 \%)$ foram positivas e com relação aos quirópteros, foram avaliadas 3.552 amostras com $58(1,6 \%)$ positivas (Tabela 1).

Tabela 1 - Relação de amostras positivas e negativas encaminhadas para diagnóstico laboratorial da Raiva na região de Presidente Prudente no período de 1996 a 2003.

\begin{tabular}{|c|c|c|c|c|c|c|c|c|c|c|c|c|}
\hline \multirow[b]{3}{*}{ Ano } & \multicolumn{12}{|c|}{ Espécie } \\
\hline & \multicolumn{2}{|c|}{ canina } & \multicolumn{2}{|c|}{ felina } & \multicolumn{2}{|c|}{ bovina } & \multicolumn{2}{|c|}{ quiróptera } & \multicolumn{2}{|c|}{ outras* } & \multicolumn{2}{|c|}{ total } \\
\hline & $\mathrm{n}$ & $\mathrm{p}$ & $\mathrm{n}$ & $\bar{p}$ & $\mathrm{n}$ & $\mathrm{p}$ & $\mathrm{n}$ & $\mathrm{p}$ & $\mathrm{n}$ & $\bar{p}$ & $\mathrm{n}$ & $\mathrm{p}$ \\
\hline 1996 & 76 & 0 & 11 & 0 & 14 & 0 & 8 & 0 & 3 & 0 & 112 & 0 \\
\hline 1997 & 82 & 0 & 20 & 0 & 12 & 2 & 17 & 0 & 3 & 0 & 132 & 2 \\
\hline 1998 & 44 & 0 & 23 & 0 & 16 & 1 & 30 & 2 & 3 & 0 & 113 & 3 \\
\hline 1999 & 43 & 0 & 22 & 0 & 38 & 2 & 62 & 1 & 5 & 0 & 167 & 3 \\
\hline 2000 & 120 & 0 & 39 & 0 & 42 & 2 & 85 & 1 & 3 & 0 & 286 & 3 \\
\hline 2001 & 119 & 0 & 51 & 0 & 26 & 1 & 142 & 1 & 6 & 0 & 342 & 2 \\
\hline 2002 & 148 & 0 & 82 & 0 & 45 & 7 & 2.162 & 37 & 9 & 0 & 2.402 & 44 \\
\hline 2003 & 190 & 0 & 88 & 0 & 12 & 1 & 1.046 & 16 & 3 & 0 & 1.322 & 17 \\
\hline Total & 822 & 0 & 336 & 0 & 205 & 16 & 3.552 & 58 & 35 & 0 & 4.950 & 74 \\
\hline
\end{tabular}

*eqüina, caprina, suína, roedores.

$\mathrm{n}=$ negativo $; \mathrm{p}=$ positivo
A Figura 1 apresenta as percentagens de amostras positivas referentes a quirópteros e bovinos em função do número de amostras encaminhadas, em cada ano.

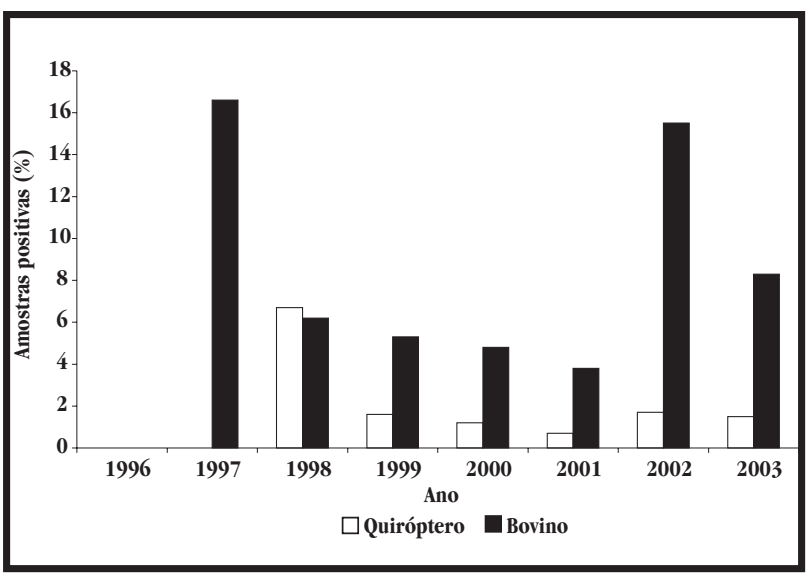

Figura 1 - Percentagem de amostras positivas, referentes aos bovinos e quirópteros, encaminhadas para diagnóstico laboratorial da raiva na região de Presidente Prudente no período de 1996 a 2003.

\section{DISCUSSÃo}

Há muitos anos que a região de Presidente Prudente mantinha estado de zona silenciosa com relação à raiva, sem apresentar casos positivos da doença, seja em animais ou pessoas. Porém, a partir de julho de 2001 com a morte de uma mulher diagnosticada com a doença no município de Dracena, a região passou a requerer uma avaliação epidemiológica mais intensa.

Após o óbito dessa mulher, fragmentos do sistema nervoso foram encaminhados para diagnóstico pelo Instituto Pasteur de São Paulo, que constatou a presença do vírus rábico. Após exaustiva investigação epidemiológica, concluiu-se que a Sra. I.M.M. de 53 anos de idade adquiriu a raiva por agressão do gato de sua propriedade. A tipificação antigênica resultou em variante 3 do Desmodus rotundus (morcego hematófago) que, provavelmente, transmitiu o vírus a um morcego não hematófago, que por conseguinte transmitiu ao gato, visto que esta variante tem sido isolada de inúmeras espécies envolvendo os morcegos não hematófagos, cães, gatos e herbívoros 5 .

Tendo em vista a situação acima descrita, houve um grande interesse pela população regional pelo fato, principalmente devido à ampla divulgação pela imprensa. Houve então, um alerta dos órgãos oficiais ligados à vigilância epidemiológica e um consequiênte aumento no envio de amostras registrado nos anos de 2002 e 2003, principalmente, de espécies de quirópteros não hematófagos.

Ainda, no ano de 2002, houve um surto de raiva em bovinos no município de Pirapózinho, também pertencente à região de Presidente Prudente. Este fato levou à morte vários animais (bovinos) que provavelmente foram contaminados por morcegos hematófagos.

Uieda cols ${ }^{11}$ citaram registros de várias espécies de morcegos positivos para raiva no Brasil e Martorelli cols ${ }^{6}$ também realizaram o isolamento do vírus em morcegos insetívoros da espécie Myótis nigricans. Carrieri cols ${ }^{1}$ realizaram estudo da 
distribuição da espécie de morcego não hematófago Artibeus sp contendo a variante 3 (Desmodus rotundus) no Estado de São Paulo no período 1998-2001.

A preocupação atual com relação ao estudo do comportamento dos quirópteros procede, uma vez que estas espécies já ocupam o segundo lugar quanto à transmissão da Raiva aos humanos, superando os felinos ${ }^{7}$.

Enquanto a região oeste do Estado de São Paulo, Presidente Prudente, possui um perfil epidemiológico mais identificado para o controle da raiva, visando os quirópteros, a região de Araçatuba, também no oeste do Estado, se preocupa mais com a raiva transmitida por cães, como demonstram os trabalhos de alguns autores ${ }^{10}$.

Roehe cols ${ }^{8}$ realizaram um estudo do diagnóstico laboratorial da raiva no Estado do Rio Grande do Sul no período de 1979 a 1984 e obtiveram um perfil bem diferente deste levantamento epidemiológico, com resultados mais focados em cães e bovinos e com pouca importância voltada aos quirópteros.

Como pode-se observar na Tabela 1 e Figura 1, o maior número de casos positivos em morcegos ocorreu nos anos de 2002 e 2003. Este fato não pode necessariamente comprovar que a região de Presidente Prudente tenha passado por um surto de raiva em quirópteros. 0 que se constatou foi um maior volume no envio de amostras para análise laboratorial tendo em vista fatores circunstanciais. Sendo assim, os percentuais de positividade foram similares aos outros anos avaliados neste trabalho (Figura 1). Provavelmente, qualquer outra região do Estado de São Paulo ou do país possa apresentar este perfil, desde que sejam enviadas amostras para análise laboratorial em proporções semelhantes.

Os autores acreditam que este trabalho possa contribuir para melhor acompanhamento epidemiológico da raiva na região pelos órgãos oficiais responsáveis por esta tarefa. Neste estudo, os autores demonstraram o perfil epidemiológico da raiva na região oeste do Estado de São Paulo (Presidente Prudente) em função das amostras encaminhadas para diagnóstico laboratorial no período de 1996 a 2003.

\section{REFERÊNCIAS BIBLIOGRÁFICAS}

1. Carrieri ML, Favoretto SRL, Cunha SEM, Silva LHQ, Albas A, Aguiar EA, Sodré MM, Kotait I. Distribution of Artibeus $s p$ with rabies variant 3 (Desmodus rotundus) in São Paulo State. 1998-2001. In: XIII International Meeting on Research Advances and Rabies Control in the Americas, 2003.

2. Dean DJ, Abelseth MK, Atanasiu P. The fluorescent antibody. In: Meslin FX, Kaplan NM, Koprowsky H (eds) Laboratory techniques in rabies, $40^{\text {th }}$ edition, World Health Organization, Geneva, p. 80-87, 1996.

3. Instituto Pasteur de São Paulo. Controle da Raiva dos Herbívoros. Manual Técnico do Instituto Pasteur, número 1, p. 1, 1998.

4. Koprowsky H. Routine laboratory procedures: The mouse inoculation test. In: Meslin FX, Kaplan MM, Koprowsky H (eds) Laboratory techniques in rabies, $40^{\text {th }}$ edition, World Health Organization, Geneva, p. 88-96, 1996.

5. Kotait I. Past. In: Raiva humana causada pela variante 3 Desmodus rotundus. Instituto Pasteur, SP, n.7, ano 4, p. 3, 2003.

6. Martorelli LFA, Aguiar EAC, Almeida MF, Silva MMS, Novaes ECR, Nunes VFP. Isolamento do vírus rábico de morcego insetívoro Lasyurus borealis. Revista de Saúde Pública 30:101-102, 1996

7. Organizacion Panamericana de la Salud. Boletin: Vigilancia Epidemiologica de la rabia en las Americas, v. XXXIII, 2001.

8. Roehe PM, Cunha AC, Rodrigues RR, Gonçalves AR, Ribeiro CLG. Diagnóstico laboratorial da raiva no Rio Grande do Sul, Brasil. Boletin de la Oficina Sanitaria Panamericana, p. 102, 1987.

9. Silva LHQ, Bissoto CE, Delbem ACB, Ferrari CIL, Perri SHV, Nunes CM. Canine rabies epidemiology in Araçatuba and neighborhood, Northwestern São Paulo State - Brazil. Revista da Sociedade Brasileira de Medicina Tropical 37:139-142, 2004.

10. Silva LHQ, Ferrari CIL, Peixoto ZMP, Cunha SEM, Gonsales CM. Diagnóstico laboratorial da raiva na região de Araçatuba no período de Janeiro/1993 a Dezembro/1995. O Biológico 58:7-12, 1996.

11. Uieda W, Hayashi NM, Gomes LH, Silva MMS. Espécies de quirópteros diagnosticadas com raiva no Brasil. Boletim do Instituto Pasteur 1:17-36, 1996. 